\title{
Research on the thinking path of enterprise management in the era of big data
}

\author{
Ying GUO \\ Qilu Normal University, China Shangdong 250013
}

\begin{abstract}
With the acceleration of economic globalization, enterprise internationalization deepen and capital supply chain extension, Chinese enterprises will inevitably was involved in the economic tide to, the business was information and data of the high-frequency explosive growth. At the same time, the rapid expansion of the management network and the management functions of the cross redundancy is serious, so that the enterprise management, decision-making, execution are subjected to tremendous impact. Big data era has arrived, companies need new management ideas and solutions to cope with the challenges of the new situation. This article embarks from the enterprise management under the background of big data, according to three aspects: production, marketing, transportation, a full range analysis to in the era of big data for scientific and effective management planning, provide strong management support for the development of enterprises.
\end{abstract}

Key Word.Big data;Intelligence;data network;Management change

\section{Introduction}

Human society has changed from the industrial age to the material and energy to the era of knowledge economy based on science and technology. The economic driving force has been transferred from the capital management and labor force to the human resources, the cultural value and the innovation of the invention. With the fifth scientific and technological revolution, following the cloud space and Internet of things, the new era of change in the Internet Era - the era of big data is coming. Economic development trajectory has been towards the knowledge assets and virtual economy closer, the traditional tangible assets, fixed assets successor weakness. Rapid development momentum forcing enterprise management mode to update, must learn from the management perspective of application of information technology to support business analysis and decision-making, strengthening and solid business operation system, so in order to better adapt to market demand.

\section{Impact on enterprise development in the era of big data} 1.1 Modern deconstruction of big data

The improvement of scientific and technological level makes people's material and cultural life

more abundant, and the popularity of mobile terminal and information network to enhance the adhesion of a huge volume of data. Data is more with the development of the Internet is a geometric multiplication, the traditional data processing methods have been difficult to control. International Data Corporation (IDC) is a digital universe on the topic research report shows: information data in 2003 the sum of only for 5EB (exabytes). Today, only 2011 statistics of world was created not to repeat the amount of data has already exceeded the 1.8ZB (zettabyte one hundred thousand million bytes), to produce $5 \mathrm{~EB}$ of the data requires only two days. And by 2020 there will be at least 25.2ZB of the total amount of data, and 70 of the 2 parties almost. And will also follow the new Moore's Law (global data over the years based, double every 
two years) continued growth!

At the same time, the complexity of the data also increased dramatically. Data types (multi-source, heterogeneous, multi source heterogeneous, multi modal, multi class grammar writing, non coherent language, grammar hybrid, etc.) are diverse, and have a high degree of random combination. In such a complex data type structure, the value of the data is very low density (there is a lot of irrelevant information, interference information and debris incomplete information) knowledge of the "purification" is more difficult. And most of the data is real-time (data requires real-time acquisition, generation, storage and analysis) and the stage (data only in a particular time period, after which will be deleted). Into the "unable to in a short period of time using conventional analysis software or tools to grab the contents of the data analysis and processing of large data set", which is widespread in social information network under the "data" intuitive deconstruction.

\subsection{Big data brought about by the era of change}

With the development of social information, the mobile network is becoming more mature, large LAN architecture is becoming more and more perfect, the amount of data created by individuals is increasingly large, big data comes also brought a time change. Big data has the characteristics of $4 \mathrm{~V}+1 \mathrm{C}$, that is, speed (Velocity), quantity (Volume), value (Value), type (Variety) and complex (complexity) to complete the summary. The huge amount of data is its basic feature, but also the prominent feature. And in this era of big data, even the most simple data sharing will give artificial become great distress, a large amount of data processing in lower operational efficiency at the same time also makes the cost of infrastructure are high, system maintenance, repair increasingly difficult, data storage has become a problem.

So at the end of 2008, three from world famous universities of information in the field of senior scientists jointly organized "computing community Alliance (computing community consortium)": the worldwide impact huge white paper "big data calculation: Social Sciences, business of the revolutionary breakthrough", make the corporate executives to realize the data real value and meaning of the times is not the data itself, but data hidden behind the powerful use. May 2011, EMC company in the cloud computing encounter big data, World 2011 conference in the big data concept and technology trends. In October of the same year, Gartner will be the big data as the first 20 thousand and 120 strategic new technology. The advent of the era of big data, but also to provide a new big data processing technology. That collects the massive data information to carry on the analysis contrast, through the data mining to create its biggest value. Subsequently, led by the United States, the United Kingdom, Germany, Finland, China have added to the application of large data technology research, the era of big data changes brought about by sweeping the globe.

\subsection{The prospect of social industry under the big data}

Large data processing technology to the surface is very wide, from medical equipment, video monitoring equipment, instruments, internet intelligent equipment, non traditional IT equipment to mobile devices and Internet information deconstruction can join the big data processing methods. Enterprises can continuously generated from trading in huge data acquisition to trillion bytes as units of consumption and supply records, to crawl "purification" such as consumer demand for goods distribution, supplier distribution ratio, capital return period enterprise management plan the core of reference data.

At present, the big data has been in the retail, financial industry, manufacturing, logistics, telecommunications, medical services, led by a large number of industries in the start, resulting 
in a huge social value and appreciation of space.

According to the professional market research firm IDC predicts that by 2010 , big data technology and business services market will grow from $\$ 17$ billion in 2015, has exceeded 100 billion, more than $50 \%$ years to achieve amazing growth rate. Had the highest growth rate of IT is less than $10 \%$ of the annual growth. Plus in recent years, domestic and foreign well-known enterprises, such as Taobao, mobile, Wal-Mart, Amazon, all have developed large data products and platforms, the use of big data technology has become a new generation of industry darling. Thus, big data in the enterprise development prospects.

\section{Enterprise management model based on big data}

Enterprise management mode with the development of information technology experienced a total of four stages of change, are based on a single stage of manual management, based on LAN online file system, based on Internet database system and based on mobile Internet data integration and analysis stage. Which promotes the management mode of the fundamental elements of constant change, is the increase in the amount of data and data types of differentiation and evolution. Now, push in the era of big data, and a data explosion, we need a new management model.

\subsection{Intelligent production}

Enterprise information system connected in factories and workshops placed sensing devices and the core control data through the integration of the physical information system (CPS), will be generated in the production of large data information through the cloud computing processing center for storage, analysis, and then draw the specific planning programs to know industrial production, which is the intelligent production management mode.

Further, is through the comprehensive production equipment data collection, access to the huge function of the production information, through the data capture and screening, for wireless communications will transmit data to the Internet, so as to realize the real-time monitoring, analysis, the Austrian data processing results feedback to the production chain, so that the entire production process for adaptive and self adjustment of intelligent network and management so as to achieve the optimization. And intelligent production, but also with the flexibility of human resources to speed up the analysis of search efficiency. For example, a Canadian named GoldCorp mining company to solve the problem of its RedLake mine veins positioning, to social media open the all the geological data in the area since 1948, in just a few weeks received a large number of Internet users in the positive feedback, and recommend users all 110 spots accurately found 80 multiple deposits, geological exploration of a large amount of money is saved.

\subsection{Big data network marketing}

Big data network marketing is the essence of the combination of marketing and the Internet, to build a cloud based platform for the marketing model. Including commodity geographic marketing, association rules mining marketing, user behavior analysis marketing, personalized marketing and big data analysis marketing. They are MapReduce parallel computing framework based on, through the collection of relevant data and with cloud platform for large data mining analysis, extract useful information integration, revised for the production of products, marketing strategy formulation, cargo personalized recommendation provide effective basic data support.

Thus in this mode, you can through the accumulation of user data, so as to compare the analysis of the customer's preferences and buying habits. And based on customer preferences to develop marketing strategy, which is the advantages and characteristics of large data network marketing. According to this, enterprises can better carry out the network 
marketing planning, to ensure the rational production of products, to protect the economic benefits of enterprises. For example, Taobao is based on large data analysis, to draw the purchase preferences of consumers, thus pushing a number of related products, thus greatly enhance the Taobao's trading volume and customer satisfaction.

\subsection{Data logistics}

Data of logistics is based on modern information data equipment (GPS, networking, mobile data terminal, GIS, cloud computing and Internet interaction, widely used in logistics transportation, loading and unloading, handling, storage, packaging, processing flow, distribution and after-sales service in the link. For enterprise products from production to sales, to carry out a full range of three-dimensional data collection, screening and analysis. Through the information network to carry out scientific scheduling, the whole process of supervision to reduce costs and potential risks, while improving the quality of logistics services.

Data logistics requires intelligent analysis, perception, optimization and real-time feedback. So big data processing cloud platform to build a key. Through the integration and reorganization of the multi-source data information, the server and data network is assimilated into a large data environment, and the data processing platform is constructed by using the matching model of intelligent terminal + data information. So as to solve the current customers, goods, courier and logistics management staff to see the current situation of information interaction and audit efficiency. In the end, the construction of the data logistics will greatly promote and accelerate the development and the rise of modern logistics business.

The management thinking and way of the enterprise should be amended with the change of the times. In today's era of big data should be closely linked to the data processing core technologyanalysis, implementation management of super flat to the data network of excessive. In order to allow enterprises to fully integrate into the era of change, and gradually optimize the enterprise system, and then to the international development.

\section{Conclusion}

The management of large data, is a new attempt in the new era, has great potential and space mining. Constructing a data management system, focused by a large number of resources, information sharing, management decision by the more broader participation, brainstorming, enhance decision-making efficiency and reduce the error probability. Also by processing the big data, cloud computing and related technology, "elastic" and "universal" and "building blocks" of the thought of technology has been popularized application, the system platform can provide ductility and durability of better quality service to customers. And in the expansion of enterprises to change the management and business module, give good technical support. And then realize the high quality, high efficiency and high intelligence of the new enterprise management mode.

\section{References}

[1] Feng Guo Xunhua. Zeng an army. Chen Guoqing Chen Yubo. Several frontier issues in business management under the background of big data $[\mathrm{J}]$ - Journal of management science 2013 (1)

[2] bell, a new management model based on large data processing [D] Hubei University of Technology -2015.06

[3] Jenny Tseng electricity business enterprise big data marketing application research [D], Guangdong University of Foreign Studies, $-2015.06$

[4]Hu Kaibao, moor-jankowski TaoQing. Corpus and translation studies: trends and problems -- 2007 international academic seminar of corpus translation studies, and research review [J]. Journal of foreign languages (journal of 
Shanghai international studies university), 2007

(05)

[5] nai-xing wei. John Sinclair linguistic heritage

- on the thought and method of [J]. Journal of foreign languages (journal of Shanghai international studies university), 2007 (04)

[6] tian zhen xie. Translation studies after the "cultural turn" - the cultural turn of translation studies in comparative literature significance $[\mathrm{J}]$. Journal of comparative literature in China. 2006 (3) 